\title{
Проживание кризиса середины жизни и стратегии совладания с ним у мужчин и женщин
}

\author{
Каринэ А. Бабиянц*, Екатерина А. ПозАнякова \\ Южный федеральный университет, г. Ростов-на-Аону, Россия \\ *E-mail: bakart@sfedu.ru
}

\begin{abstract}
Аннотация
В статье рассматриваются представления о протекании кризиса середины жизни у мужчин и женщин в отечественной и зарубежной психологической и меАицинской науках. Приводится содержательный анализ Аанного периола жизни У взрослых АюАей, акцентируются отличительные особенности выраженности стратегий совлаАания с кризисом у мужчин и женщин. Эмпирическим объектом исслеАования являлись 61 женщина и 45 мужчин в возрасте от 35 Ао 50 мет, разного социального статуса, различной профрессиональной приналмежности и уровня образования, никак не связанные межАу собой. Описывается анализ авторской анкеты о содержании кризиса середины жизни, а также анализ проживания кризиса середины жизни по методике ^. Г. Петрявской «Кризисы развития». Новизна исследования заключается, во-первых, в существенном Аополнении преАставлений о проживании кризиса середины жизни мужской выборкой, поскольку чаще всего в эмпирических исслеАованиях приводятся исслеАования респонАентов-женщин определенной профрессиональной приналлежности (педагоги, психологи). По авторскому замыслу мужская выборка фрормировалась случайно и не бы^а связана с профрессиональной приналлежностью. Во-вторых, новизна исследования заключается в Аифроеренцированном анализе проживания кризиса середины жизни в разнополых группах.

Представлены результаты Аифореренциального исследования, Аоказывающие наличие сходных и отличительных особенностей проживания кризиса середины жизни у мужчин и женщин. Высказывается мысль о необходимости эорорективного выхода из периола кризиса середины жизни, гАе основным направлением является сбалансированность стратегий совлаАания в разных сорерах жизни у мужчин и женщин, при наличии различного солержания этих сорер.
\end{abstract}

\section{КАючевые слова}

кризис, середина жизни, мужчины, женщины, стратегии совладания, половые различия, Аифрореренциация, сореры жизни, выхол из кризиса 
ПСИХОЛОГИЯ РАЗВИТИЯ

Аля цитирования: Бабиянц К. А., ПозАнякова Е. А. Проживание кризиса середины жизни и стратегии совлаАания с ним у мужчин и женщин // СевероКавказский психологический вестник. 2020. № 18/2. С. 77-91. doi: 10.21702/ ncpb.2020.2.6

\title{
Living a mid-life crisis and coping strategies in men and women
}

\section{Karine A. Babiyants*, Ekaterina A. Pozdnyakova}

Southern Federal University, Rostov-on-Don, Russia

* Corresponding author. E-mail: bakart@sfedu.ru

\begin{abstract}
The article demonstrates the ideas about the course of the midlife crisis in men and women in domestic (Russian) and foreign psychological and medical sciences. A meaningful analysis of this period of life in adults is given, the distinctive features of the severity of strategies for coping with the crisis in men and women are emphasized. The object of the study was 61 women and 45 men, aged 35 to 50 years old, of different social status, different professional affiliation and educational level, not in any way related to each other.

The authors describe the analysis of the authors' questionnaire on the content of the midlife crisis and the analysis of the technique "Development Crises" by L. G. Petryavskaya. The novelty of the study lies, firstly, in a significant addition to the notions of living through a mid-life crisis by the male sample, since most often empirical studies cite subjective research data of female respondents of a certain professional affiliation (teachers, psychologists). According to the author's intention, the male sample was carried out randomly and was not associated with professional affiliation. Secondly, the novelty of the study consisted in a differentiated analysis of the midlife crisis in different sex groups.

The article presents the results of a differential study, proving the presence of general psychological phenomena of the midlife crisis and the presence of distinctive features in different groups. The idea is expressed about the need for an effective way out of the midlife crisis, where the main focus is on the balance of coping strategies in different spheres of life for men and women, in the presence of different content of these spheres. The content of the balance model was revealed among the tested respondents of both sexes.
\end{abstract}

\section{Keywords}

crisis, middle of life, men, women, coping strategies, sex differences, differentiation, spheres of life, way out of the crisis 
For citation: Babiyants K. A., Pozdnyakova E. A. Living a mid-life crisis and coping strategies in men and women. Severo-Kavkazskii psikhologicheskii vestnik = North-Caucasian Psychological Bulletin, 2020, no. 18/2, pp. 77-91. doi: 10.21702/ ncpb.2020.2.6 (in Russ.).

\section{ВВЕДЕНИЕ}

Кризис середины жизни является наиболее интенсивным в периоде взрослости как для мужчин, так и для женщин. Возникнув, кризис требует затрат жизненных сил, а также психологической концентрации, веры в себя, стойкости, смелости, умения «держать удар», терпения, умения преодолевать трудности, порой субъективно переживаемые как непереносимые,-т. е. всего того, что в период кризиса середины жизни как раз теряет свою выраженность. Именно в период кризиса физические силы, психологическая решимость, когнитивный настрой и эмоциональное состояние приближаются к низким отметкам $[1,2,3]$. По мнению Н. Пезешкиана, немецкого психотерапевта персидского происхождения, основавшего в 1967 г. Висбаденскую академию позитивной психотерапии, в определенном периоде онтогенеза могут актуализироваться конфликты именно в той сфере жизни, которая оказывается в дефиците. Например, если человек отдавал всего себя работе в ущерб своему здоровью, то этот дефицит даст о себе знать и в психосоматическом и в физиологическом проявлении; если много пребывал в контактах и забросил дела, то непременно начинают рушиться планы, отменяться контракты, заканчиваются деньги [4]. Очень яркие метафоры на этот счет есть у русского народа: «семь бед - один ответ» [5, с. 25], «пришла беда - отворяй ворота» [5, с. 55]. Смысл кризиса в том и состоит, чтобы свершились какие-то перемены, однако мы не всегда к ним готовы. Даже тогда, когда мы ждем перемен и желаем, чтобы в нашей жизни что-либо изменилось.

Считается, что самыми активными в поисках новых стратегий, ощущений и воплощений являются мужчины. Их полоролевая идентичность предписывает им быть активными, инициативными, проявлять мужественность в рискованных и часто экстремальных поступках, а также быть крайне нетерпеливыми [6, 7]. Но эти стратегии хороши, когда есть очевидный кризис, и отчетливо видна сфера, требующая внимания. Кризис же середины жизни часто протекает пролонгировано, не имеет четких границ и в то же время неуклонно способствует нарушению привычного хода событий, привычного стереотипного существования; часто мы не понимаем, что происходит, не видим очевидных причин, поэтому накапливается тревожность, подавляются или вытесняются неприятные ощущения, проявляется импульсивность [8, 9]. Недаром у психологов есть поговорка, которая очень ярко отражает именно кризис середины жизни: «седина в голову - бес в ребро». О чем она? Американский исследователь 
ПСИХОЛОГИЯ РАЗВИТИЯ

и писатель Э. Роббинс считает, что период кризиса середины жизни, хоть и протекает пролонгировано и скрыто, относительно поступков очень похож на резкий вираж, когда коренным образом пересматривается весь жизненный замысел, трансформируются до противоположных ценности, жизненные сценарии редактируются, а личность испытывает практически трансцендентные эмоциональные переживания [10]. У К. Г. Юнга было свое мнение насчет кризиса середины жизни. Он считал, что до периода кризиса середины жизни люди очень много сил и энергии отдают социализации, персонификации для того, чтобы можно было адаптироваться в обществе. Однако часто персонификация становится лидирующим процессом, на фоне которого индивидуация снижается, тогда самый серьезный кризис человека как раз и связан с осознанием, что «вся первая половина жизни прожита не ради истинного себя, а ради требований общества, ради персоны... для человека это сильнейший удар, он чувствует себя жестоко обманутым, что и служит причиной тяжелого кризиса...» [11, с. 10]. Человек часто не понимает, как быть индивидуальным, поскольку социальные институты и средства массовой информации предлагают нам индивидуальность через товары потребления и стандартные способы совладания, опять-таки, принятые в обществе большинством, и тогда индивидуальность уже не является таковой, она - не что иное, как усредненный вариант персонификации. Такое осознание усиливает переживание кризиса [11].

Чем наполнен кризис середины жизни? В отличие от кризиса 30-ти лет, когда корректируются планы, изменяются притязания, т. к. они становятся очевидно нереалистичными, в отличие от кризиса зрелости в 65 лет, когда заканчивается активная трудовая деятельность и важно принять свой опыт, свой путь, свои ошибки. Ощущением последнего шанса? Потребностью выполнить свою миссию и страхом не успеть или потребностью самовыразиться? Ощущением безвозвратно и бесцельно уходящего времени? А, может быть, ощущением нивелированной собственной ценности?

Как мужчины справляются с этими вопросами? Часто приходит «на помощь» импульсивность: изменить все - семью, работу, место жительства, образ жизни, при этом в разных вариациях - от обливания холодной водой и пробежек по утрам до «беспробудных запоев». Это можно назвать делинквентным поведением - уход в работу, экстремальные виды спорта, частая смена половых партнеров после 25-летнего семейного стажа, а иногда и смена сексуальной ориентации. Либо другой вариант - «не сдаваться ни при каких обстоятельствах»приводит на больничную койку, поскольку ресурсы, и так минимизированные, окончательно истощаются. Все эти факты указывают на то, что мужчины редко умеют по-настоящему эмоционально проживать свои проблемы, не умеют об этом говорить, не позволяют себя жалеть, либо не признаются сами себе, что проблема существует, и нужна помощь $[12,13,14,15]$. 
Кризис середины жизни затрагивает множество разных сфер - личностную, профессиональную, экономическую, физическую, экзистенциальную. Считается, что для мужчины самым тяжелым является кризис в возрасте 37-42 лет, который сопрягается с вступлением в «фазу увядания». Центром этой фазы является страх потери потенции, которая равносильна утрате мужской идентичности. Самыми распространенными симптомами считаются возникновение тревоги и раздражительности, перепады настроения и мнительность, повышение конфликтности, упадок жизненных сил и чувство одиночества, ощущение пессимизма и бесперспективности. Все эти ощущения и эмоциональные переживания неразрывно связаны и являются оборотной стороной экзистенциальных переживаний: конкретно о смысле жизни, о том, что имеется на сегодняшний день и что это уже никогда не изменится, о конечности жизни $[12,16]$.

Одним из ярких показателей наличия кризиса середины жизни является крайнее расхождение между рефлексией «чего я хочу?» и «что я получил?». Чем больше реализаций и воплощений - тем ниже интенсивность кризиса, поскольку чувство собственной полноценности является мощным ресурсом личности. Этот феномен одинаково присущ и мужчинам и женщинам. Однако женщинам намного тяжелее переключиться на реализацию в деятельности, т. к. обычно в этот период вырастают и становятся самостоятельными дети, привычные женские заботы становятся невостребованными, а реализация в профессиональной деятельности обрастает страхами не справиться, не успеть, не воплотить свои мечты $[6,7,12,16,17]$.

Самым важным, на наш взгляд, аспектом переживания кризиса середины жизни, как мужчинами, так и женщинами, является умение обрести необходимые ресурсы для возможности совладать с кризисным периодом.

Если принять за аксиому, что кризисы неизменно ведут к развитию, то, конечно, и кризис середины жизни рано или поздно приведет к новому переосмыслению, принятию, изменению. Обычно выделяют два сценария этих перемен: один про то, что люди пытаются активно наладить, изменить что-то в своей личной, профессиональной, экономической жизни, и со временем, независимо от того, насколько эффективно это у них получается, острота кризиса уходит, и происходит принятие неизбежности перемен. Второй сценарий - про то, как наиболее ярко и осмысленно прожить остаток жизни, как научиться получать удовольствие от жизни, как найти новые смыслы и реализовать свою идентичность. Это наиболее конструктивный подход, который возможен только благодаря осознанности и рефлексии $[8,9,12]$.

Часто психиатры и психотерапевты сравнивают мужской кризис середины жизни с женской утратой фертильности, которая часто сопровождается накалом неконтролируемых эмоций, пониженным фоном настроения, 
ПСИХОЛОГИЯ РАЗВИТИЯ

физиологическими «приливами» потливости,- всем тем, что связано с гормональной перестройкой (именно поэтому часто кризис середины жизни сравнивают с подростковым кризисом). Врачи-эндокринологи, психиатры и психотерапевты настаивают на том, что в жизни мужчины в период кризиса середины жизни обязательно должна быть физическая нагрузка, которая дает ощущение преодоления и победы, ощущение усталости в мышцах, нагрузки, - все эти состояния способствуют увеличению тестостерона. Также можно помогать себе медикаментозно, увеличивая количество тестостерона в организме. Психотерапия здесь является дополняющим и очень существенным помощником. В то время как у женщин происходит более глубокая гормональная перестройка, и одними антидепрессантами справиться невозможно, необходима коррекция эмоционально-волевой сферы. Однако феноменология протекания кризиса середины жизни у женщин так глубоко не затрагивает смысложизненную сферу. Женщины в основном стремятся адаптироваться к физиологическому изменению и к новому статусу в семье, когда уже не нужно заботиться о выросших детях и еще не нужно заботиться о вполне самостоятельных родителях, и можно больше внимания уделять собственной реализации. Мужчины же очень глубоко испытывают ощущение «последнего шанса», «нереализованности»; некоторые психотерапевты сравнивают это состояние с психозом, в рамках которого нужно преодолеть «рубикон», после которого назад пути нет, а впереди неизвестно, что ожидает $[18,19]$.

Есть и другое мнение экспертов по возрастному развитию: о том, что кризис середины жизни - это миф, что это самое время расцвета для личности, когда есть опыт, экономическая независимость, реализация в профессии. Вот как высказывается психолог и писатель Э. Роббинс: «Проблема в том, что общество путает мужчину средних лет с полуостывшим трупом. То, что называют кризисом среднего возраста, часто просто первые признаки жизни, подаваемые ими после многих лет комы» [10, с. 23]. Отечественные психологи Г. А. Чернявская и И. Ф. Петров, изучив приоритеты жизни у людей среднего возраста, отметили, что «только 10-26\% людей старше 40 лет переживают именно кризис, поэтому, возможно, было бы уместнее говорить о переходном периоде среднего возраста» [20, с. 188].

Такого же мнения придерживается Д. Левинсон, утверждающий, что в период середины жизни каждый человек начинает осознавать, что он перестает быть молодым, что наступают физиологические изменения, поэтому следует говорить о переходе, а не о глобальном кризисе [21, 22]. Н. Вее считает, что «изменения в среднем возрасте предсказуемы и закономерны, и каждый человек может их предвидеть» [18, с. 55], а, следовательно, подготовиться к ним, снижая тем самым риск кризисного прохождения данного этапа. 
По-настоящему остро проживается, по его мнению, период после 60-ти лет, когда физические изменения и социальная усталость дают о себе знать [18].

\section{Цель, объект}

Короткий теоретический обзор указывает на недостаточное количество работ, содержащих сравнительный анализ особенностей проживания мужчинами и женщинами кризиса середины жизни, поэтому мы посвятили исследование этому вопросу. В нем принимали участие 61 женщина и 45 мужчин в возрасте от 35 до 50 лет. Все респонденты с разным социальным статусом, с разным уровнем образования и профессиональной принадлежностью.

\section{МЕТОДЫ}

Для того чтобы провести сравнительный анализ проживания кризиса середины жизни мужчинами и женщинами, мы создали анкету, где основным вопросом был следующий: «как Вы думаете, что чаще всего испытывает человек в кризисе середины жизни?». Целью анкеты являлся сбор информации о том, как мужчины и женщины чувствуют себя в основных сферах жизнедеятельности в этот период. К основным видам жизнедеятельности мы отнесли: ведущую деятельность в профессиональном плане; сферу межличностного взаимодействия и коммуникаций; сферу ощущений и эмоций; сферу смыслов, ценностей, интересов и планирования будущего. Обоснованием для исследования именно этих четырех сфер послужила теория Н. Пезешкиана о том, что быть здоровым и реализовавшимся человеком можно только в том случае, когда все основные сферы жизни сбалансированы [4]. Также мы использовали методику Л. Г. Петрявской «Кризисы развития» о содержании кризисов в жизни мужчины и женщины [см. 23].

\section{РЕЗУЛЬТАТЫ И ИХ ОБСУЖДЕНИЕ}

Мы сопоставили показатели мужчин и женщин по двум методикам. По методике Л. Г. Петрявской «Кризисы развития» мы обнаружили, что относительно критерия «кризисы в профессиональной жизни» и мужчины и женщины очень устают от работы (56\% мужчин, 62 \% женщин), тяжело адаптируются к профессии (33\% мужчин, 43 \% женщин).

Наиболее отличительными показателями между группой мужчин и группой женщин являются «потеря смысла в профессиональной деятельности» (у женщин $48 \%$, у мужчин $22 \%$ ) и «неудовлетворенность самореализацией в работе» (у женщин 57 \%, у мужчин 22 \%). Это доказывает, что общепсихологическим, универсальным для обоих полов феноменом, связанным с переживанием кризиса середины жизни, является «страх потерять работу». В то же время, показатели свидетельствуют о том, что женщины в меньшей степени могут 
ПСИХОЛОГИЯ РАЗВИТИЯ

реализовать свои интенции в работе и чаще теряют смысл в профессиональной деятельности.

Содержательный анализ, полученный при помощи авторской анкеты, указывает на то, что большинство женщин (82\%) не удовлетворены той деятельностью, которой они занимались на момент тестирования, однако у них очень высокий потенциал поиска и реализации копинг-стратегий в сфере деятельности. Они активно приобретают новые знания (82 \%), что в два раза выше, чем у мужчин (42\%), активно ищут место для самореализации (62 \%), в то время как мужчины осуществляют поиск в 47 \% случаев; женщины переобучаются (54\%), что гораздо активнее происходит, чем у мужчин (20\%). В то же время мы можем говорить о том, что содержательным акцентом в сфере деятельности для мужчин и женщин является поиск новых возможностей для самореализации и приобретения новых знаний с лидирующим превосходством в активности женщин.

По методике Л. Г. Петрявской обнаружено, что для мужчин и женщин одинаково важна возможность самореализации (для 27 \% мужчин и $39 \%$ женщин). Также им свойственна тревога относительно отсутствия гарантий будущего (24\% мужчин, 33 \% женщин).

Существенное отличие в переживании личностных кризисов наблюдается у женщин относительно «коррекции жизненных планов» $(62 \%)$ и «неудовлетворенности самой собой» (62\%), «сожаления об ушедшей любви» (34\%) и «потери смысла жизни». Последний показатель в процентном отношении невелик, однако он существенно выше у женщин (23\%), в то время как мужчин захватывает такое переживание лишь в $9 \%$ случаев из $100 \%$.

Опираясь на данные авторской анкеты, мы получили возможность более детально рассмотреть содержание личностного аспекта кризиса середины жизни. Мы рассмотрели сферу контактов и сферу телесности мужчин и женщин. Было обнаружено, что в контактах ведущим фактором является традиционное взаимодействие в межличностном отношении в кругу семьи, родственников и других значимых людей. А также очень важным критерием является отношение к самому себе и, в том числе, к своему телесному образу. Мы обнаружили, что самый яркий показатель неудовлетворенности в сфере контактов у мужчин и у женщин проявляется в «потере интереса к друзьям» (у $44 \%$ мужчин и 51 \% женщин), в том, что «не о чем говорить с друзьями» (у 42 \% мужчин и $33 \%$ женщин), в «скуке в отношениях» (у 31 \% мужчин и $29 \%$ женщин).

Проживая кризис середины жизни, меняется отношение к друзьям, оно становится аффективно окрашенным: для женщин чаще свойственно раздражение (36\%), для мужчин - агрессия (24\%).

В отношении с супругами самый выраженный показатель у женщин - это «отсутствие сексуального влечения» к партнеру (42\%), у мужчин он выражен 
в $13 \%$. Женщины чаще испытывают раздражение к партнеру или супругу (44\%) и в $21 \%$ случаев утвердительно отвечают на пункт «испытываю досаду, что рядом именно этот человек».

В то же время часть респондентов испытывает следующие негативные переживания: «отсутствие интереса к партнеру» (20\% мужчин и $25 \%$ женщин), при этом обе стороны склонны искать «схожих по интересам людей» (36\% женщин и 22 \% мужчин); «ощущение пустоты и одиночества» (20\% мужчин и $29 \%$ женщин) и «потребность остаться одному» (16\% мужчин и $23 \%$ женщин).

В отношении детей и родителей женщины более склонны испытывать обиду на родителей (38 \%) и заботу о детях (34\%), в то время как у мужчин больше выражена тенденция заботиться о родителях (31\%).

Относительно сферы телесности мы обнаружили, что в этот возрастной период некоторые взрослые пренебрегают своим физическим состоянием (36\% женщин и 20 \% мужчин); другая часть женщин имеет отрицательное эмоциональное восприятие своей телесности (39\%). По данным авторской анкеты на вопрос «хотелось бы Вам изменить свою внешность, и если хотелось, то каким образом?» $24 \%$ мужчин и 23 \% женщин дали положительный ответ. Вот наиболее частые высказывания женщин о способах изменения своего внешнего вида: «приблизить свое тело к идеальному видению красоты», «похудеть», «изменить цвет волос», «изменить длину волос, прическу», «выглядеть моложе за счет косметических процедур для лица» (инъекции, массажи, пилинг, наращивание ресниц, бровей, ногтей, волос и т. д.), «заняться спортом». Мужчины видят, в основном, два ведущих способа изменить свою внешность больше отдыхать от рабочих нагрузок и заниматься спортом.

По показателям физического самочувствия все респонденты указывают на чрезмерную усталость и невозможность расслабиться (36 \% мужчин, 41 \% женщин).

Л. Г. Петрявская в своей методике «Кризисы развития» выделяет так называемые «событийно-биографические» факторы, подчеркивая тем самым важность жизненных событий, влияющих на протекание кризиса середины жизни. В таком событийно-биографическом аспекте для мужчин и женщин одинаково фрустрирующим является фактор «потеря работы» (у $27 \%$ мужчин и 21 \% женщин) и, вопреки ожиданиям, маленький процент респондентов обоего пола переживает «уход из семьи выросших детей» (по 7 \%).

Существенным отличием можно считать женскую неудовлетворенность в своем «социальном положении» (36\%), беспокойство по поводу «смены места жительства» (25\%), беспокойство о «здоровье и состоянии близких» (38\%), «неудовлетворенность внутрисемейным положением» (57\%).

Исследования по авторской анкете прояснили ценностно-смысловое содержание кризиса середины жизни. По сфере фантазий, которая существует 
ПСИХОЛОГИЯ РАЗВИТИЯ

посредством смыслов, ценностей, образов о желаемом и перспективном будущем, интересов, верований и желаний, мы увидели, что и у мужчин и у женщин в кризисе середины жизни теряется «источник радости, то, что раньше приносило удовольствие, теперь не приносит удовлетворения» (36\% мужчин, 56 \% женщин). Женщины в большей степени задумываются о «потере смысла жизни» (46\%) и «потере ощущения счастья» $(46 \%)$, у мужчин эти показатели, соответственно, $16 \%$ и $11 \%$. И мужчины и женщины переживают фрустрацию из-за потери «цели в жизни» (36\% мужчин, 31 \% женщин) и «отсутствия желаний» (33\% мужчин и $26 \%$ женщин).

На основе проведенных исследований мы составили таблицу способов совладания в кризисной ситуации для мужчин и женщин. Было обнаружено, что у женщин намного более выражена и разнообразна образная сфера, в которой перерабатываются знания (таблица 1).

Таблица 1

Сравнительный анализ распреАеления способов совлаАания в кризисе сереАины жизни у мужчин и женщин

\begin{tabular}{|c|c|c|c|c|}
\hline & $\begin{array}{l}\text { Фантазии } \\
\text { (образы, } \\
\text { смыслы, } \\
\text { ценности, } \\
\text { будущее) }\end{array}$ & $\begin{array}{c}\text { Контакты } \\
\text { (тралиции) }\end{array}$ & $\begin{array}{c}\text { Аеятель- } \\
\text { ность } \\
\text { (пове- } \\
\text { дение, } \\
\text { мышление) }\end{array}$ & $\begin{array}{c}\text { Телесность } \\
\text { (ощущение, } \\
\text { эмоции) }\end{array}$ \\
\hline Женщины & $\begin{array}{l}\text { Чтение } \\
\text { ^итературы } \\
\mathbf{6 2 \%} \\
\text { Смена } \\
\text { впечатлений, } \\
\text { поезАки, } \\
\text { путешествия } \\
\mathbf{5 9 \%} \\
\text { Обретение } \\
\text { новых } \\
\text { интересов } 46 \% \\
\text { Искусство } \mathbf{3 4 \%}\end{array}$ & $\begin{array}{l}\text { Арузья и их } \\
\text { подлержка } \\
48 \% \\
\text { Беседы } \\
\text { с психологом } \\
46 \% \\
\text { Новая любовь } \\
\text { и дружба } 36 \% \\
\text { Общение } \\
\text { с новыми } \\
\text { мало- } \\
\text { знакомыми } \\
\text { Аюдьми } 31 \% \\
\text { Занятия } \\
\text { в группах } \\
\text { по интересам } \\
26 \%\end{array}$ & $\begin{array}{l}\text { Поиск } \\
\text { нового } \\
\text { места } \\
\text { Аля само- } \\
\text { реализации } \\
62 \% \\
\text { Занятия } \\
\text { в системе } \\
\text { повышения } \\
\text { квали- } \\
\text { оикации } \\
46 \% \\
\text { Научное } \\
\text { расши- } \\
\text { рение } \\
\text { картины } \\
\text { мира } 41 \%\end{array}$ & $\begin{array}{l}\text { Занятие } \\
\text { спортом } \\
\text { и внешним } \\
\text { виАом } 35 \% \\
\text { 3Аоровый } \\
\text { образ } \\
\text { жизни } 26 \%\end{array}$ \\
\hline
\end{tabular}




\begin{tabular}{|c|c|c|c|c|}
\hline & $\begin{array}{l}\text { Фантазии } \\
\text { (образы, } \\
\text { смыслы, } \\
\text { ценности, } \\
\text { будущее) }\end{array}$ & $\begin{array}{c}\text { Контакты } \\
\text { (традиции) }\end{array}$ & $\begin{array}{c}\text { Аеятель- } \\
\text { ность } \\
\text { (пове- } \\
\text { дение, } \\
\text { мышление) }\end{array}$ & $\begin{array}{c}\text { Телесность } \\
\text { (ощущение, } \\
\text { эмоции) }\end{array}$ \\
\hline Мужчины & $\begin{array}{l}\text { Смена } \\
\text { впечатлений, } \\
\text { поездки, } \\
\text { путешествия } \\
\mathbf{2 2 \%} \\
\text { Развлечения, } \\
\text { отвлечение } \\
\text { от проблем } \\
\mathbf{2 0 \%} \\
\text { Обретение } \\
\text { новых } \\
\text { интересов } 18 \%\end{array}$ & $\begin{array}{l}\text { Арузья и их } \\
\text { подлержка } \\
27 \% \\
\text { Семья и лети } \\
\mathbf{3 8 \%} \\
\text { Обрести } \\
\text { группу едино- } \\
\text { мышленников } \\
16 \%\end{array}$ & $\begin{array}{l}\text { Поиск } \\
\text { нового } \\
\text { места } \\
\text { А^я само- } \\
\text { реали- } \\
\text { зации } 47 \% \\
\text { УхоА } \\
\text { в работу } \\
18 \%\end{array}$ & $\begin{array}{l}\text { Занятие } \\
\text { спортом } \\
35 \%\end{array}$ \\
\hline
\end{tabular}

Эта сфера существует за счет смыслов и ценностей, расширения интересов, планирования будущего. Также у женщин достаточно представлены сфера деятельности (они стремятся повышать свою квалификацию, расширять научную картину мира) и сфера контактов, где обретение новых знакомств, формирование новых традиций, опора на поддержку друзей являются сильными способами совладания с кризисным периодом.

Мужчины оказываются менее активными, чем женщины, в реализации сферы деятельности: они не стремятся к научному расширению картины мира (0\%), стремятся уйти в работу (18\%), немногие занимаются в системе повышения квалификации (7\%), однако они активно ищут новые возможности для самореализации (47\%). Более выраженными являются стратегии в коммуникативной сфере: стремятся обрести группу единомышленников (16\%), общаться с друзьями и опираться на их поддержку (27\%), однако общение с психологом совсем не входит в арсенал мужчин (0\%), занятия в группах по интересам также остаются невостребованными (0\%). Особенно интересным фактом мы посчитали возрастание у мужчин склонности уделять больше внимания и времени семье - и детям и престарелым родителям (38\%). Показатели, касающиеся сферы фантазии, выражены у мужчин малым интересом к новому (18\%), малым интересом к чтению литературы и искусству (9\% и 11 \%), 
ПСИХОЛОГИЯ РАЗВИТИЯ

слабым интересом к путешествиям и развлечениям (22 \% и $20 \%$ ), при этом выражено стремление отвлекаться от проблем (20\%).

Такой анализ дает представление о том, что более адаптивными в проживании кризиса середины жизни являются женщины: они более сбалансированно подходят к переработке жизненных проблем, в то время как мужчины не имеют широкого и сбалансированного диапазона совладания с ситуацией глубокого переживания возрастного кризиса.

\section{Выводы}

В результате проведенного анализа мы можем предположить, что существуют общие закономерности проживания возрастных кризисов, свойственные как мужчинам, так и женщинам. К ним относятся:

1. В профессиональной сфере: усталость от работы и тяжелая адаптация к профессии, тревога по поводу потери работы, поиск новых возможностей для самореализации и приобретения новых знаний, фрустрация по поводу «нереализованных возможностей».

2. В эмоциональной сфере доминируют: тревога по поводу отсутствия гарантий будущего, потеря источника радости и цели жизни, потеря способности испытывать желания. В сфере контактов теряется интерес к друзьям, усиливаются негативные эмоциональные переживания и разочарования по отношению к своим супругам, переживается ощущение пустоты и одиночества.

3. В сфере телесности часто проявляется пренебрежение своим физическим состоянием и внешним видом, либо активные поиски изменения у мужчин с помощью спорта и отдыха, у женщин с помощью спорта, здорового образа жизни и косметических интервенций.

Существенно выражены и отличия в проживании кризиса середины жизни у мужчин и у женщин, они проявляются в следующем:

1. Женщины чаще задумываются о смысле профессиональной деятельности, они чаще не удовлетворены собственной реализацией в этой сфере, однако обладают более высоким потенциалом совладания в кризисной ситуации, более активны в переориентации и поиске нового вида деятельности.

2. Женщины легче относятся к необходимости коррекции жизненных планов, поскольку большинство из них (62\%) не удовлетворены собой, сожалеют об ушедшей любви, они в большей степени испытывают снижение сексуального влечения к партнеру (42 \%) и неудовлетворенность внутрисемейным положением.

3. У женщин выражены различные способы совладания в кризисной ситуации, в которые входит сфера телесности, сфера деятельности и сфера 
контактов, и доминирующую роль выполняет сфера фантазий и образов.

4. Мужчины оказываются менее активными, чем женщины, в реализации сферы деятельности; более выраженными являются стратегии в коммуникативной сфере.

\section{ЛИТЕРАТУРА}

1. Ганзен В. А., Головей Л. А. К системному описанию онтогенеза человека // Психология развития: Хрестоматия. СПб.: Питер, 2001. С. 81-97.

2. Манукян В. Р. Нормативные кризисы развития в период взрослости // Вестник СПбГУ. Сер. 12. 2010. Вып. 1. С. 39-45.

3. Солодников В. В., Солодникова И. В. «Кризис среднего возраста»: теоретическая интерпретация переживаемого опыта // Мониторинг общественного мнения. 2009. № 4. С. 178-202.

4. Пезешкиан Н. Психотерапия повседневной жизни: тренинг разрешения конфликтов. СПб.: Речь, 2001. 288 с.

5. Русские крылатые выражения. Сборник / Сост. Н. Е. Фомина. Харьков: Фолио, 2009. 224 с.

6. Ижванова Е. М. Развитие полоролевой идентичности в юношеском и зрелых возрастах: дисс. ... канд. психол. наук. М., 2004. 181 с.

7. Чернобровкина С. В. Гендерные особенности переживания и преодоления кризиса середины жизни // Вестник Омского университета. Серия «Психология». 2014. № 2. С. 30-42.

8. Ипполитова Е. А. Особенности представлений о жизненных перспективах личности в период кризиса середины жизни: дисс. ... канд. психол. наук. Барнаул, 2005. 196 с.

9. Солдатова Е. Л. Нормативные кризисы развития личности взрослого человека: дисс. д. психол. наук. Челябинск, 2007. 375 с.

10. Роббинс Э. Разбуди в себе исполина. М.: Попурри, 2017.

11. Ануров Д., Маслова Ю. Архетип счастья. Всё, что нужно знать об аналитической психологии Карла Густава Юнга. М.: АРДИС, 2017.

12. Ливехуд Б. Кризисы жизни - шансы жизни: Развитие человека между детством и старостью. Калуга: Духовное познание, 1994. 217 с.

13. Мастерс У., Джонсон В., Колодны Р. Мастерс и Джонсон о любви и сексе. СПб.: Ретур, 1991. Т. 1. 264 с.

14. Поливанова К. Н. Психология возрастных кризисов. М.: Academia, 2000. 180 с.

15. Baltes P. B., Reese H. W., Lipsitt L. P. Life-span developmental psychology // Annual Review of Psychology. 1980. Vol. 31. P. 65-110. DOI: $10.1146 /$ annurev. ps.31.020180.000433

16. Шихи Г. Возрастные кризисы. Ступени личностного роста. СПб.: Ювента, 1999. 
ПСИХОЛОГИЯ РАЗВИТИЯ

17. Леонтьев Д. А. Психология смысла: Природа, строение и динамика смысловой реальности. М.: Смысл, 2003. 486 с.

18. Bee H. The journey of adulthood. MacMillan Publishing Company, 1986. 446 p.

19. DelVento Bielby D., Perun P.J.Structure and dynamics of the individual life course // Life course: Integrative theories and exemplary populations / Ed. by K. Back. Boulder, CO: Westview Press, 1980.P.97-119.DOI:10.4324/9780429052194-7

20. Чернявская Г. А., Петров И. Ф. Наиболее важные жизненные приоритеты у людей среднего возраста // Аллея Науки. 2018. № 10. С. 186-191.

21. Levinson D. J. The seasons of a man's life. New York: Knopf, 1978.

22. Levinson D. J. The seasons of a woman's life. New York: Knopf, 1996.

23. Марчук Е. А. Кризисы взрослого периода у женщин // Актуальные проблемы психологии личности: сб. науч. ст. / Под науч. ред. К. В. Карпинского. Гродно: ГрГУ, 2010. С. 22-37.

\section{REFERENCES}

1. Ganzen V. A., Golovei L. A. Towards a systemic description of human ontogenesis. In: Developmental Psychology: Chrestomathy. St. Petersburg, Piter, 2001, pp. 81-97. (in Russ.).

2. Manukyan V. R. Normative crises of the development in the period of adulthood. Vestnik SPbSU. Ser. 12, 2010, Issue 1, pp. 39-45. (in Russ.).

3. Solodnikov V. V., Solodnikova I. V. "Midlife crisis": Theoretical interpretation of the lived experience. Monitoring obshchestvennogo mneniya = Monitoring of Public Opinion, 2009, no. 4, pp. 178-202. (in Russ.).

4. Pezeshkian N. Psychotherapy of everyday life: conflict resolution training. St. Petersburg, Rech', 2001. 288 p. (in Russ.).

5. Fomina N. E. (Comp.). Russian winged expressions. Collection. Kharkov, Folio, 2009. 224 p. (in Russ.).

6. Izhvanova E. M. The development of gender-role identity in adolescence and adulthood (Candidate Dissertation). Moscow, 2004. 181 p. (in Russ.).

7. Chernobrovkina S. V. Midlife crisis: Features of experience and coping behavior of men and women. Vestnik Omskogo universiteta. Seriya «Psikhologiya»= Herald of Omsk University. Series "Psychology", 2014, no. 2, pp. 30-42. (in Russ.).

8. Ippolitova E. A. Features of ideas about the life prospects of the individual during the midlife crisis (Candidate Dissertation). Barnaul, 2005. 196 p. (in Russ.).

9. Soldatova E. L. Normative crises of development of the personality of an adult (Doctoral Dissertation). Chelyabinsk, 2007. 375 p. (in Russ.).

10. Robbins A. Wake up the giant in yourself. Moscow, Popurri, 2017. (in Russ.).

11. Anurov D., Maslova Yu. The archetype of happiness. Everything you need to know about the analytical psychology of Carl Gustav Jung. Moscow, ARDIS, 2017. (in Russ.). 
12. Livekhud B. Life crises - life chances: Human development between childhood and old age. Kaluga, Dukhovnoe poznanie, 1994. 217 p. (in Russ.).

13. Masters W., Johnson V., Kolodny R. Masters and Johnson about love and sex. St. Petersburg, Retur, 1991, V. 1. 264 p. (in Russ.).

14. Polivanova K. N. The psychology of age crises. Moscow, Academia, 2000. 180 p. (in Russ.).

15. Baltes P. B., Reese H. W., Lipsitt L. P. Life-span developmental psychology. Annual Review of Psychology, 1980, V. 31, pp. 65-110. DOI: 10.1146/annurev. ps.31.020180.000433

16. Sheehy G. Age crises. Stages of personal growth. St. Petersburg, Yuventa, 1999. (in Russ.).

17. Leontiev D. A. The psychology of meaning: Nature, structure and dynamics of meaning reality. Moscow, Smysl, 2003. 486 p. (in Russ.).

18. Bee H. The journey of adulthood. MacMillan Publishing Company, 1986. 446 p.

19. Del Vento Bielby D., Perun P. J. Structure and dynamics of the individual life course. In: K. Back (Ed.). Life course: Integrative theories and exemplary populations. Boulder, CO, Westview Press, 1980, pp. 97-119. DOI: 10.4324/9780429052194-7

20. Chernyavskaya G. A., Petrov I. F. The most important life priorities for middleaged people. Alleya nauki, 2018, no. 10, pp. 186-191. (in Russ.).

21. Levinson D. J. The seasons of a man's life. New York, Knopf, 1978.

22. Levinson D. J. The seasons of a woman's life. New York, Knopf, 1996.

23. Marchuk E. A. Crises of the adult period in women. In: K. V. Karpinskii (Sc. Ed.). Actual problems of personality psychology: Collection of scientific articles. Grodno, GrSU, 2010. pp. 22-37. (in Russ.). 